\title{
Best Practices in Institution Reform in Africa
}

\author{
By Paul Ntungwe Ndue
}

Possibilities for African governments to be effective depend largely on their being responsive to national aspirations. The issues of good governance for any country is both a situational one, because of culture differences, and a normative one, lending from success stories of other countries. The choice of type of polity needs to be a localised national design incorporating the local perceptions of good in terms of laws, organisation, roles and accountability. This paper suggests six questions that may help to assess these.

Politics have been described as the art of determining who gets what, where, and when. This paper proposes a more developmental meaning of politics: the practice of advocacy in pursuit of overall social stability for an embracing sustainable socio-economic development of a people. The roles of constitutions and institutions are then reviewed for their contribution to social stability and economic development. In this regard the paper also calls for examination of inter-relations between governance and contract and investment.

\section{Introduction}

First, my understanding is that my brief task is to bring to the fore critical issues in institution reform within the context of strategically led and managed nations. I wish to acknowledge that accepting responsibility for a willed future entails acknowledging and addressing the serious leadership and managerial weaknesses militating against development. ${ }^{1}$ However, I propose that accepting this responsibility in a meaningful and useful way largely involves determining the critical leadership and managerial traits requisite for development. After all, if you do not know where you are going and how to get there, any direction may do. At this level, because of the principle of sovereignty of states, it is ultimately only the states which may best determine their destinies. Unless this happens or the O.A.U. and other external partners adopt alternative acceptable and irresistible intervention strategies very little may be achieved. Again according to Adedeji ${ }^{2}$ the African crisis is essentially a political crisis, albeit with serious socio-economic consequences.

1

African Association for Public Administration and Management (AAPAM), Preliminary Notes and Information on the Nineteenth Roundtable Conference, AAPAM 1997.

2

Adedeji, Adebayo, What Prospects for Nigerian Political Economy in the Next Millenium?, in: Africa Today: The Voice of the Continent, London 1997. 
My premise is going to be that in any group or community something has worked and something works. ${ }^{3}$ The challenge for collective leadership is to create a sense of shared destiny by negotiating a common agenda on development issues; and this sense of a shared identity can only be carried out if we focus on our similarities and not our differences. Safe that where such differences have been allowed to manif est themselves to extremes, as in the case of the Hutus and Tutsis, it may be that relocation may present itself as a viable option. Throughout this paper I am going to argue for participation of indigenous communities in the determination of type of polity and institutional design. People feel confident when they carry into the future what has worked for them in the past.

Crudely, I see two types of African countries: those which have not experienced the turmoil of political violence and have relative political stability ${ }^{4}$ such as Botswana, Côte d'Ivoire, the Gambia, Madagascar, Mauritius, Senegal; and the second type which has been tormented by political violence and civil strife. "... any attempt to consider the question by taking into account all possible alternatives would be excessively complex" ${ }^{5}$ and may be not so fruitful as the situation varies greatly between countries. The distinctive feature in most, if to all, of the former type is that they were all indigenous democracies with very deep African cultures that had emerged from African traditional institutions and practices.

Literature on institutional reforms is generally divided according to two general approaches: i) the normative approach which seeks to adapt best practices based on experiences, empirical designs and theoretical analysis; and ii) the situational approach which calls for action research into local values, culture and indigenous participation in institutional design and reform. I have opted for the latter approach. According to Przeworski ${ }^{7}$ leaning just from "success" leads to biased inferences: this is just elementary statistics. Unless we have an understanding of the reasons a particular policy was chosen to begin with, our inferences about effect of the policy on performance are likely to be biased. If the policy was chosen for reasons that also affect performance, one cannot expect that it would have had the same effect under different conditions. For this reason I shall later review some thoughts on the effect of culture'on institutions.

Hammond, Sue Annis, Appreciative inquiry, Plano1996, p. 20.

I see political stability as a relative concept referring to the extent of dynamic political equilibrium which still yields acceptable degrees or levels of economic performances, both macro and micro, including the virtue of (relative) equitable distribution.

Boeninger, E., Governance and Development: Issues and Constraints, in: Annual Conference on Development Economics, Washington D.C.: World Bank 1991, p. 271.

6

Mbigi, L., Ubuntu: The African Dream in Management, Pretoria 1997, p. 22.

Przeworski, A., Comment on Impact of Constitutions on Economic Performance on Development Economics, Washington D.C.: World Bank 1994, p. 231. 
In demonstrating the importance of institutions, the World Bank has used the example of the East Asian Miracle. One of the attributable factors of the East Asian economic success of the existence of strong institutional frameworks in all the concerned economies. Among the specific aspects of the institutional framework are:

- competent, honest, and realistically paid bureaucracies

- early development of legal and regulatory frameworks

- creation of formal institutions and informal channels to facilitate communication between the public and the private sector. ${ }^{8}$

On the other hand, AAPAM says that the cumulative impact of the decay of public service institutions and values has brought to the fore the issue of the role of the state in the development process. ${ }^{9}$ In this regard the World Bank provides a definition with three distinct features: i) the form of political regime; ii) the process by which authority.is exercised in the management of a country's economic and social resources for development; and iii) the capacity of governments to design, formulate, and implement policies and discharge functions. ${ }^{10}$ Note is taken here that the World Bank deems the first aspect outside its mandate!

The World Bank also indicates that the African Development Bank suggests that authoritarian regimes committed to development might exhibit good governance at the middle and lower levels of government. Mbigi ${ }^{11}$ says that political dictatorship is alien to African culture. While one will generally agree, it may be difficult to classify Chaka as a democratic leader. The important point here is that considerations for economic development are to lost.

The World Bank indicates that the Inter-American Bank gives special emphasis to the modernization of public administration; and that the OECD's Development Assistance Committee, while using the World Bank's definition, links it with democratization, including media freedom, transparency and accountability. I submit that these features are inherent in the traditional African democracies which, incidentally, were not hereditary before colonialisation. According to Mazrui ${ }^{12}$ the continent has much in its indigenous past to form the foundation of its democratic future. ${ }^{13}$ I assume that in playing its governance role in the above manner, the state's purpose is to enhance its responsiveness to the needs of

World Bank, Development in Practice Governance: The World Bank Experience, Washington D.C. 1994.

9

AAPAM (Fn. 1), p. 23.

10 World Bank (Fn. 8).

11

Mbigi (Fn. 6), p. 27.

12 Mazrui, A., Ubuntu: The Africans - A Triple Heritage, New York 1987.

13 See also Mbigi (Fn. 6): Ubuntu: The Spirit of African Collective Leadership and Ubuntu in the Political Kingdom. 
its people. I believe also that in developing response-managed institutions, the OECD's concern for modernization will be incorporated.

\section{History of Institutional Development}

At and after independence the task of nation building and national integration had to be the most difficult to handle. This had to be so because, among others, in many instances new leadership did not coincide with the hither-to-fore traditionally accepted leadership which had previously epitomised (national) unity. The political party leadership did not incorporate, in most parts, the old African cultural or ethnical leadership. In Botswana, for instance, Sir Seretse Khama condescended chieftainship (albeit for other reasons) and took party political leadership-nation building and integration has proved to be less difficult than many other to handle. If there was a one-party regime here, it was never through known coercion. The transitional arrangements formed a good base for future stability; and this has to be treasured. African socialism on the eve and at the dawn of independence, on the other hand, symbolised continuation of the common struggle against colonialism for independence. In a number of cases this enhanced initial nation building. The short-term goal would not be self-sustaining for nation building and long-term economic development.

The "traditional management style" of the colonial master could only last while the native perceived a benefit of protection and some sense of security. The management style persisted its duration nurtured by lack of honest sentiment between master and native. The sale of labour for protection and essential (primary) products exchanged for luxury products became a fertile breeding ground for transactional leadership traits in the more privileged natives - they perceived charisma in the white master; and the white master says: "If you do as I tell you then you will some day be like me and enjoy the things I enjoy." The master was and is still envied - appeal to narcissism. ${ }^{14}$

The evolutionary process through industrialization had been halted and was still stalled, and the old ethnic and acquired religious vertical polarisations remained and coincided and reinforced themselves with the new affiliations. ${ }^{15}$ After independence the new African transactional leaderships were entrenched, and the loyalty to be transacted was political party support, ethnicity or religion. These were invariably equivalent. The valuable and palatable reward was position in the civil service. The institution could only decay. The legislative branch could not evade decay as the very first and prime rewards would have been positions in party leadership guaranteeing, for the top brass, positions in the legisla-

14

See Sashkin, M. / Rosenbach, William E., Contemporary issues in Leadership, in: William E. Rosenbach / Robert I. Taylor (eds.), 3rd. ed., Washington D.C. 1993.

15

See also Museveni, Yoweri K., Sowing the Mustard Seed, London 1997, p. 187. 
ture, and queuing for the executive. The lingering colonial judiciary would soon be replaced by the Africans, opening lucrative and tenure-secured reward opportunities for special legal support. ${ }^{16}$

This sure-remedy for catastrophe could not logically tend towards sustainable-development than to self-sustenance called self-interest seeking (with guile). The majority of governments has perfected and expanded the repressive structures that the colonial governments had left in place. ${ }^{17}$ This situation had to endure: "... politics is the art of determining who get what, where and when. ... politics is essentially a transaction ...". ${ }^{18}$ Given definitions like this it is possible, therefore, for the following advice to be proffered and swallowed stock - and barrel: "... if an election is approaching, some ... groups ought to be returning to the support sectors ... divide and conquer, playing one group off another, both are viable strategies." ${ }^{19}$ The construance of politics to mean simple allocation of resources implies the crudest form of opportunism paralleled nowhere even in transactional approaches. "Power is exchange (even if only symbolically so). ... this conception of power appears to be contradictory: on the one hand, authority, as such, deserves the expression of respect, but expression of respect does not suggest the obligation to comply with orders, since, on the other hand, authority always arouses suspicion. ${ }^{20}$ Africans must define their own politics.

\section{Culture and Institutional Reform}

"... effective organisation is an amalgam of organisational imperatives and variables, valuebased imperatives, and cultural practices which either already are, or can be made, compatible with them." ${ }^{21}$ That is, even in societies that contain many ethnic groups and that are characterised by moral pluralism, there is nonetheless some core at which some basic values converge. ${ }^{22}$ Values are in the foundation of organisational culture; and it is in the interests of today and tomorrow's organisations and nations to manage their affairs strategically. Organisational culture, however, impacts far more than the process and outcomes of

Tenure-security is now entrenched; see United Nations, Basic Principles on the Independence of the Judiciary, New York 1988, p. 6.

17 Mbigi (Fn. 6), p. 22.

18 Crosby, Benjamin L., Management and the Environment for Implementation of Policy Change, Part one, in: Implementing Policy Change: Technical Notes, Washington D.C.: USAID 1992, p. 2. Crosby (Fn. 18), pp. 8-9.

20 Martin, D.-C., The Cultural Dimensions of Governance, in: Annual Conference on Development Economics, Washington D.C.: World Bank 1991, p. 333.

Blunt, Peter, Strategies for Enhancing Organisational Effectiveness in the Third World, in: Public Administration and Development, 10 (3) 1990, pp. 299-313, p. 308.

Martin (Fn. 20), p. 336. 
strategic planning. Its consequences for over-all organisational effectiveness are even more profound. ${ }^{23}$ Research thus should hone in on that core of shared cultural values to identify, in each society, how culture preconditions the emergence of good governance, and how it may be possible to use the actual and popularly perceived power of the state to develop the quality of governance. ${ }^{24}$ It is an indisputable fact that nations cannot be built without the full participation of the people. ${ }^{25}$

The dominance of the culture and values of the industrial democracies has put increasing pressure on societies that do not have the same social traditions. Local conditions are central to sorting out the challenges, constraints, and priorities for political and economic reform. ${ }^{26}$ Sustainable democracy has to be built on the practices and values of African indigenous institutions. ${ }^{27}$ Already this approach has been recognised and used to develop the Zambian civil service reform programme. ${ }^{28}$ Schein $^{29}$ provides a comprehensive definition of culture: a pattern of basic assumptions, invented, discovered or developed by a given group as it learns to cope with its problems of external adaptation and internal integration, that has worked well enough to be considered valid and, therefore, is taught to new members as the correct way to perceive, think and feel. In seeking to achieve synergistic national performances it is, therefore, instructive to exploit the cohesiveness brought about by national culture. In order for political democracy to flourish in Africa, it must be underpinned by very deep cultural roots and nourished by the fertility of economic prosperity. ${ }^{30}$ In this regard Martin ${ }^{31}$ suggests a series of questions that might serve as a basic guide for further research. I have added two to his list:

- What do people consider good?

- What do people consider as good governance? (my addition - to attach purpose to responses to the following questions.)

- What are the most trusted and effective types of social organisation?

- What should be the role of the governed in good governance? (my addition - this should help to explicate and clarify the type and minimum extent of popular participation.)

Goodstein, L. / Nolan, T. / Pfeiffer, J. William, Applied Strategic Planning, New York 1993, p. 68.

Martin (Fn. 20), p. 336.

Adedeji (Fn. 2), p. 7.

26 Boeninger (Fn. 5), pp. 269-270.

Mbigi (Fn. 6), p. 22. 
- How should those who seek good governance deal with the pervasive distrust of power and the state?

- What will serve as the basis of local ideas of accountability?

In the words of Fine ${ }^{32}$ the responses must come from Africans themselves. Broad ownership and support of the renewed institutions can best be achieved through broad-based participation in the institutional reform process, including determination of purpose of reform, and purposes to be served by the institutions; and according to Van Arkadie ${ }^{33}$ : rules and organisation. Again according to Museveni ${ }^{34}$ we must ensure that our political institutions spring from our social structure. If we are to develop we must evolve institutional models which will liberate us from our backwardness. If there is an indispensable and irreducible prerequisite for good governance, it would appear to be the need for all social and political actors to refer to ... a shared ensemble of ethical values. ${ }^{35}$. These can only be explicated by those who hold them.

\section{Role of the State}

"... a critical task of government ... is to provide the 'right' incentives to stimulate and guide the various actors in the economy ... that development policy must focus on the institutional arrangements that provide the setting in which the incentive system will operate. ${ }^{36}$ Though views may differ as to what the right incentives are, I interpret them as incentives which best cause the various actors to achieve response - competitiveness for their various customers or co-dependent customer chains. ${ }^{37}$ These incentives will vary from country to country, but invariably they include catalytic or enabling public goods without necessarily converting countries into welfare-states. The state must foster education, for the entirety of its people, that makes them aware of their economic rights and responsibilities; and foster education that makes its people aware of their social and political rights and responsibilities and facilitates the exercise of such rights and responsibilities. And according to Mbigi ${ }^{38}$ it is also equally important to create political empowerment of minority ethnic groups by

Fine, Jeffrey C., Sub-Saharan Africa: Its Prospects for Growth, in: Whither African Economies, OECD 1995.

Van Arkadie, Brian, The Role of Institutions in Development, in: Annual Conference on Development Economics, Washington D.C.: World Bank 1989.

Martin (Fn. 20), p. 335.

36 Van Arkadie (Fn. 33), p. 161.

37 See Levit, Steve, Quality is just the Beginning: Managing for Total Responsiveness, New York 1994. 
placing a deliberate emphasis on a traditional African consensus democracy of village assembly. The task of collective leadership is to create economic and organisational citizenship for the majority and political citizenship for the minority ethnic groups.

Governments must be symbols of national unity; they must assume transformational leadership roles and lead their nations towards development and achievement of common national purposes. And according to Camdessus ${ }^{39}$ there is no sustainable development without sound responsible management of public affairs. This means that governments must first and foremost lead and manage countries towards achievement of explicit, common and shared national purposes. This includes frugality in resources management.

\section{Constitutions}

According to Elster ${ }^{40}$ the general role of constitutionalism is to make it more difficult to change constitutional provisions. He argues that constitutionalism is one precommitment solution to the problem of strategic time inconsistency. It is possible, however, that governments may still default from such precommitment. On the other hand though, Sen ${ }^{41}$ stresses that constitutions must guarantee the exercise of two rights: free speech to publicise abuses, and political rights to enable people to vote the abusers out of office. ${ }^{42}$ Given such rights with the concomitant education, constitutionalisation of economic efficiency thus would result in enhanced government accountability and transparency. Yet, Przeworski's ${ }^{43}$ caution is still pertinent: constitutionalism may promote commitment, but not every commitment is to good policies. ... even if we knew the impact of institutions on policies, we should remain sceptical about institutional prescriptions. The independence of the (judiciary and) central banks, for instance, may not be a prescriptive one. ${ }^{44}$

Camdessus, Michael, Facing the Globalized Economy: The IMF Experience, Washington D.C.: IMF 1996, p. 28.

40 Elster, Jon, The Impact of Constitutions on Economic Performance, in: Annual Conference on Development Economics, Washington D.C.: World Bank 1994, pp. 218-219.

41 Sen, A., "Equality of What?", in: A. Sen (ed.), Choice, Welfare, and Measurement, New York 1982.

42 For example see the constitution of Lesotho, Article 87: A Political party was formed in parliament (June 1997) and became the government without elections, while Article 87 was meant to provide guidance on the appointment of Prime Minister after elections.

Przeworski (Fn. 7), p. 227.

44 See Bardhan, Pranab, Comment on the Impact of Constitutions on Economic Performance, by: $J$. Elster, in Annual Conference on Development Economics, Washington D.C.: World Bank 1994, p. 233. 
Cohesive and strategically managed nations will work towards the realization of common purposes. Independence within such contexts therefore becomes relative autonomy; decisions and practices of which must be guided, evaluated against a common values-system, ratified or sanctioned for their contribution to the common purpose by the inbuilt multiplicity of veto powers with the system. When governments and government institutions perceive of themselves and each other as being parts of co-dependent customer chains, then issues of (total) independence and separation of powers become decreasingly significant on and of their own: the chain then functions towards common purposes - response competitiveness with the final consumer as the focal point - and the elements constitute multiple veto powers, causing even corrupt transactions to be increasingly less certain and corruption itself more costly than otherwise. ${ }^{45}$

\section{Institutions}

In discussing institutions I believe it is important first to contextualise them. Institutions function within political frameworks. In contrast to Crosby's definition of politics ${ }^{46}$, I wish to propose here an expanded meaning of politics as: the practice of advocacy in pursuit of overall social stability for an embracing sustainable socio-economic development (of a people). It is against this understanding of politics that I discuss the roles of institutions.

But the issues of democracy also requires clarity. According to Przeworski ${ }^{47}$ : observed values show higher investment share in democracies. Przeworski continues: while the question of whether democracy fosters or hinders economic growth is politically important labelling political institutions as democratic or authoritarian does not capture institutional features that are relevant to economic growth. Contrarily, however, Przeworski defines democracy as a regime in which some government offices are filled as a result of contested elections. But this can only be one of the features of democratic practice; and indeed it may not help us much to understand the contribution of democracies to economic development and growth. The significant difference between democratic practice or democracy and good governance may only be in the election process. It would appear, though, that investments are important for high economic performance: the nature and level of investment and characteristics of contracting are important. ${ }^{48}$ To emphasise the importance he adds: “... more durable assets will be supplanted by less-durable assets. ... assets may flee by

45

46

47

48

See Bardhan (Fn. 44), pp. 233-234.

Crosby (Fn. 18).

Przeworski (Fn. 7), p. 230.

Williamson, Oliver E., The Institutions and Governance of Economic Development and Reform, in: Annual Conference on Development Economics, Washington D.C.: World Bank 1994, pp. 180-181. 
relocating in more secure jurisdictions. ... non-redeployable investments ... that would be made in a secure investment regime will be supplanted by more redeployable assets and by capital flight and asset concealment. Productivity will be lost as a result. ... nations with problematic judiciaries will be ... disadvantaged."

Since investment, durable-investment, leads to economic development, it ought to be an important responsibility for government institutions to foster and fulfil. According to Przeworski ${ }^{49}$ investment rises with per capita income. And Azam ${ }^{50}$ asserts that redistribution policies are a major ingredient in peace-making policy. Also: One of the causes of poverty in developing countries is precisely that poor groups do not matter much to the political life of the countries. ${ }^{51}$ Another responsibility of government institutions thus becomes the promotion, formulation and implementation of redistribution policies and strategies requisite for social stability and peace.

Political parties not in government and those wishing to context for positions in government should not see themselves as oppositions. They are governments in waiting. Their major preoccupation must be in the envisioning of strategies to enhance and improve government and national social stability and economic performance. Institution reform will be for void, is the individual to remain unreformed.

50 Azam, T.-P., Development Policy for Africa: A Research Agenda, in: Whither African Economies, OECD 1995, p. 72. Africa", in: $R$. van der Hooven / F. van der Kraaij (eds.), Structural Adjustment and beyond in Sub-Saharan Africa, The Hague 1994, pp. 100-113. 